\title{
A Review of Online Product Reviews
}

\author{
Huifen Wang, Yang Wang \\ Department of Business Administration, Jinan University, Guangzhou, China \\ Email: jun0909wy@163.com
}

How to cite this paper: Wang, H.F. and Wang, Y. (2020) A Review of Online Product Reviews. Journal of Service Science and Management, 13, 88-96. https://doi.org/10.4236/jssm.2020.131006

Received: December 16, 2019

Accepted: February 4, 2020

Published: February 7, 2020

Copyright $\odot 2020$ by author(s) and Scientific Research Publishing Inc. This work is licensed under the Creative Commons Attribution International License (CC BY 4.0).

http://creativecommons.org/licenses/by/4.0/ (c) (i) Open Access

\begin{abstract}
In the rapidly growing Internet of China, online shopping has spread to the daily lives of most people. Consumers need to consider the characteristics, quality, price, and other information of the product when making purchases on the Internet platform, and carefully select them to improve the satisfaction of shopping. Online product review is one of the sources of product feature information and is increasingly valued by online consumers. This article will review the literature of online product reviews from the generation of online product reviews, outcome variables, usefulness, and influencing factors. We will sort out current academic achievements, and look for future research directions. Follow-up researches should use scientific analysis techniques and methods to establish theoretical models, and explore the mechanism of usefulness of online product reviews.
\end{abstract}

\section{Keywords}

Online Product Reviews, Perceived Usefulness, Online Buying Behavior

\section{Introduction}

With the popularization of shopping on the Internet, many consumers released their shopping experience on the e-commerce platform which became the online reviews of products. The multi-dimensional information conveyed by these reviews provides important references for consumers to choose appropriate products. In the research, the concept of online product reviews is defined as a kind of electronic word-of-mouth written and released by consumers on the Internet, which enables people to easily obtain the opinions and personal experiences of different products from unknown individuals [1]. Due to the rapid development of e-commerce, researches on online product reviews are increasing. The article will sort out these literatures from the aspects of the generation, consequences and influencing factors of online product reviews. 


\section{The Generation of Online Product Reviews}

\subsection{Consumer Participation Motivation}

Shao Bingjia et al. applied the social exchange theory to explore the factors that influence Chinese consumers' participation in online product reviews. The theory of social exchange regards the active behavior between people as a rational behavior to calculate the benefit and loss of individuals. The theory believes that the motivation of individual behavior is to maximize the benefit and minimize the cost. Shao Bingjia et al. believe that word-of-mouth can be regarded as a social exchange behavior, through which consumers provide relevant shopping experience in order to obtain valuable feedback for them, such as pleasure, prestige. Benefit factors in social exchange theory are those results that can provide positive value. Shao Bingjia et al. summarized these favorable results into four points: the first is the pleasure gained from helping others; the second is the pleasure gained by influencing the enterprise; the third is obtaining self-improvement and the fourth is economic rewards. In the theory of social exchange, the cost factors refer to the negative results which will weaken people's enthusiasm for exchange behavior. For online review behavior, cost factors include cognitive cost and implementation cost, in other words, the emotional impact of recalling the shopping experience and the time and effort spent in online review. The structural equation model is used to analyze the influence factors. The results show that the pleasure gained from helping other consumers and the pleasure gained by influencing enterprises can have a positive impact on consumers' intention to participate in online product reviews. The implementation cost of online reviews has a negative impact on consumers' intention to participate in online product reviews [2]. From the research, it can be seen that consumers have two major motivations when conducting online product reviews: helping other consumers and influencing enterprises. The sense of accomplishment and pleasure brought by these two behaviors makes consumers more willing to participate in online reviews. The implementation costs of conducting online reviews inhibit the willingness of consumers.

\subsection{The Popularity of the Product}

From the perspective of product popularity, Chrysanthos \& Guodong Gao explored whether consumers' online review behavior can influence the information competition between popular products and niche products. The question was answered by investigating the relationship between people's propensity to post online reviews of different products in the same category and the popularity of those products. They believe that most movie reviews are released after consumption, which have a wide range of timeliness and availability. Therefore, the empirical data was from online reviews published by consumers on Yahoo Movie. The analysis showed that, other things being equal, consumers were more likely to comment on the products which were lack of availability and less successful in the market, and they were also more likely to provide reviews for ro- 
ducts that were already commented by others. These two opposing forces result in a $\mathrm{u}$-shaped relationship between the average tendency of people to post online reviews after watching a movie and the film's weekly box office: moviegoers seem more likely to provide online reviews for very obscure movies and very high-grossing ones [3]. Their research suggests that the popularity of a product has an impact on consumers' online review behavior: consumers are more likely to post reviews for a hit or niche product than a mediocre one.

\subsection{User Interaction}

Paulo B. Goes thought that readers and publishers of online comments could form relationship to influence each other. They explored the impact of interaction on the behavior of online comments, including the frequency, the content and the expressing way. They collected data from a website where users could subscribe to each other to study these issues. By applying panel data and flexible matching methods, they found that as users became more popular, they generated more reviews and the reviews were more objective. And their ratings also changed systematically, becoming more negative and diverse [4]. They demonstrated the impact of user interactions on the number and content of online reviews.

\subsection{Self-Selection Biases}

$\mathrm{Nan} \mathrm{Hu}$ put forward that there were two kinds of self-selection biases in online product reviews which caused J shape curve: acquisition bias refers that mostly consumers with a favorable predisposition acquire a product and hence write a product review and underreporting bias refers that consumers with extreme, either positive or negative, ratings are more likely to write reviews than consumers with moderate product ratings [5].

\section{Outcome Variables for Online Product Reviews}

\subsection{Product Sales and Revenue}

Dellarocas found that the valence (the mean of ratings) of online reviews was a better predictor of future box-office revenue than other indicators [6]. Duan argued that the number of online reviews had a significant impact on box-office sales [7]. Eric K. Clemons explored the causal relationship between online product reviews and sales by a study of the craft beer industry. According to the results, while the number of online reviews is a good predictor of sales of a single beer product, there is no significant correlation between the average rating of online reviews and product sales. According to the results, while the number of online reviews is a good predictor of product sales, there is no significant correlation between the average rating of online reviews and product sales [8].

\subsection{Consumers' Beliefs}

Benlian argued that supplier recommendations and consumer reviews had dif- 
ferent effects on personal beliefs and e-commerce transaction intentions. In the process of consumers making purchase decisions, supplier recommendation played a role as an active promotion, while consumer review was a summary of their purchasing and using experience directly released information to other consumers. Benlian investigated the differential effects of provider recommendations and consumer reviews on the instrumental, affective, and trusting dimensions. He divided the products into search products and experience products. And there were four consumer beliefs: perceived usefulness, perceived ease of use, perceived affective quality and trust. The empirical study revealed that supplier recommendations showed significantly higher perceived usefulness and perceived ease of use, while consumer reviews expressed higher perceived affective quality and trust [9].

\subsection{Competition between Upstream Manufacturers}

Young Kwark explored the impact of online product reviews on competition among manufacturers in the supply chain. Online product reviews provided additional information to consumers, reduced uncertainty about product quality and improved the matching-degree of consumer needs. The study found that quality information made consumers feel the same about the two products and intensified competition among upstream suppliers, which was good for retailers but bad for manufacturers. While demand matching information heterogeneous, the suitability of products to consumers alleviates the competition among upstream suppliers, benefiting manufacturers but adversely affecting retailers [10].

\subsection{Consumers' Preference for Product Attributes}

Although online reviews can help consumers assess the product more accurately, it is believed that complex and contradictory information in online reviews could make it difficult for consumers to identify and consider product attributes relevant to their decisions. Qianqian Ben Liu argued that online reviews could have a swing effect on consumers' preferences for product attributes. The research showed that there were three characteristics of online products affect consumers' preference for product attributes: the amount of information about product attributes, the degree of conflict over product attributes and the correlation between numerical ratings and product attributes [11].

It can be seen from the literature that the role of online product reviews is mainly manifested in two aspects. On the one hand, it is an objective product market. Online product reviews can affect product sales, revenue, and market competition. On the other hand, it is the subjective beliefs of consumers. Online product reviews can influence consumer judgment on products through information dissemination. However, the impact is two-sided. It may not only actively promote the usefulness of reviews, but also cause decision-making difficulties for consumers. 


\section{Factors That Influence the Usefulness of Online Product Reviews}

Yang Shuang explored the effect mechanism of the usefulness of online product reviews by researching virtual communities. He suggested that empathy and identity mediated the usefulness of online product reviews. The empirical results showed that information quality and community status had positive effects on perceived usefulness, and empathy is the internal mechanism of this effect. For high involvement products, information quality plays a greater role in empathy and perceived usefulness. For low involvement product, community status has a greater effect on perceived usefulness [12].

Credibility is defined as the degree to which people believe that the source of information provided is unbiased, reliable and true [13]. Users would consider the motivation of reviewers when reading reviews. Based on attribution theory, consumers tend to attribute negative reviews to internal products and believe that reviews are credible and useful, while tend to attribute positive reviews to external reviewers and feel that comments lacked credibility [14].

Cao analyzed the characteristics of online comments text deeply from the perspective of format and semantic meaning. The results showed that consumers considered extreme comments more useful, with semantic features playing a major role [15].

Yin Guopeng studied the influence factors of the usefulness of online comments with the perspective of information adoption and social network. He found that the attention level of reviewers positively affected the usefulness of their comments and there was a threshold. However, when the threshold value is exceeded, the negative correlation effect appears, showing an inverted u-shaped relationship [16].

Zhang Yanhui explored the factors that influence the usefulness of online reviews in terms of the moderating effect of product types. The results showed that the higher the credit rating of reviewer and the longer the review, the more useful the review. For experience products, reviewers' credit rating, valence of reviews, additional comments and sellers' response affect the usefulness of online review significantly. For search products, uploading images is a major influence on the usefulness of online comments [17].

Huang Yunhui investigated the impact of online review on consumer product assessment in terms of the readability of fonts. The study found that legibility of fonts increased the impact of online reviews on consumers by increasing credibility [18]. In addition, when consumers clarify information thoroughly, the impact of online review fonts will diminish, so legibility of fonts cannot be used to judge the impact of online reviews.

Yan Qiang explored the factors that influenced the perceived usefulness of online reviews by the empirical research of online film reviews. Through data analysis of 37,393 actual user comments from douban.com, he concluded that extreme emotions and length of comments positively affect the perceived useful- 
ness of online reviews, while the valence, title length and readability of the comment had no significant effect on the perceived usefulness [19].

Tingting Song explored the effects of social relationship, shopping phase and transaction scarcity on the effectiveness of online product recommendations. The results showed that when transaction scarcity was low, product recommendations with a weak social relationship were more convincing in the initial shopping phase than those with a strong social relationship, while in the later shopping phase, product recommendations with a strong social relationship were more convincing than those with a weak social relationship. In the initial and later stages of shopping, the difference from the impact of social relationship strength on product recommendation persuasion disappeared when transaction scarcity was extremely high [20].

Blanca explored the moderating effect of psychosocial distance on the usefulness of online product reviews from three characteristics of reviewers: the profile photos, writing styles and personal experiences they expressed. The research showed that if profile photos of reviewers could create a sense of familiarity to consumers, the psychosocial distance between them would be shortened and the comments would be more effective. If the reader's language style is similar to the reviewer's, their psychosocial distance will be decreased and the perceived credibility and usefulness of online reviews will be increased. Sharing personal experiences increases the usefulness of comments by creating trust between reviewers and readers which can shorten the psychosocial distance [21].

\section{Research Result}

The author classified the above factors into direct influence and indirect influence. These direct acting factors were further divided into the features of reviews, the characteristics of reviewers and the preferences of readers. The moderating effects were from shopping situation factors and emotional factors. The details were shown in Table 1 and Table 2.

Table 1. The direct acting factors on the usefulness of online product reviews.

\begin{tabular}{ccc}
\hline The way of influence & Factors & Layers \\
\hline Quality of information & & \\
Length of reviews & Features of reviews \\
Semantic meaning & \\
Emotional tendency & Fonts of reviews \\
Community status & \\
Sirect acting & Pource credibility & \\
& Popularity & \\
& Characteristics of reviewers
\end{tabular}

Data source: summarized by the author. 
Table 2. The moderating factors of the usefulness of online product reviews.

\begin{tabular}{ccc}
\hline The way of influence & Factors & Layers \\
\hline Type of products & \\
Transaction scarcity & Shopping situation \\
Shopping phase & \\
Empathy & Characteristics of reviewers \\
Identity & \\
\hline
\end{tabular}

Data source: summarized by the author.

\section{Research Prospect}

\subsection{Try to Explore the Deep Mechanism of Influence}

It can be seen from the literature review that there have been many studies on the usefulness of online product reviews, but most of them use empirical methods and cross-sectional data to test the hypothesis of the correlation between the influencing factors. They have not delved into the mechanisms that actually trigger the usefulness of online product reviews. Therefore, researchers can explore the causal relationship between the influencing factors at multiple levels to make the mechanism clearer.

\subsection{Look for Internal Regulators}

Yunhui Huang found that the readability or readability of online review fonts affected both the usefulness of online reviews and the credibility of reviewers, while Yan Qiang argued that readability of online comments had no significant effect on perceived usefulness. Why two different conclusions? Researchers can explore the influence of external environmental factors or other regulatory variables on the relationship between review readability and perceived usefulness.

\subsection{Establish Theoretical Models to Clarify the Complex Effects}

In the paper, the author briefly summarized the 15 influencing factors of online product reviews. With the help of scientific methods, researchers can integrate influencing factors in a comprehensive way and establish theoretical models to form a system.

\section{Fund Project}

National Natural Science Foundation of China: Research on the Mechanism of Online Symbolic Action to Consumer Drift (71761003).

\section{Conflicts of Interest}

The authors declare no conflicts of interest regarding the publication of this paper. 


\section{References}

[1] Purnawirawan, N., Pelsmacker, P.D. and Dens, N. (2012) Balance and Sequence in Online Reviews: How Perceived Usefulness Affects Attitudes and Intentions. Journal of Interactive Marketing, 26, 244-255. https://doi.org/10.1016/j.intmar.2012.04.002

[2] Shao, B.J., Ma, R. and Zhang, X.Y. (2010) Empirical Study on Factors Influencing Intention of Consumers to Participate Online Product Review. Journal of Intelligence, 185-189. https://doi.org/10.2316/P.2011.704-020

[3] Dellarocas, C., Gao, G. and Narayan, R. (2010) Are Consumers More Likely to Contribute Online Reviews for Hit or Niche Products? Journal of Management Information Systems, 27, 127-158. https://doi.org/10.2753/MIS0742-1222270204

[4] Paulo, B. and Goes, M.L. (2014) "Popularity Effect” in User-Generated Content: Evidence from Online Product Reviews. Information Systems Research, 19, 182-201.

[5] Nan Hu, P.A.P. (2017) On Self-Selection Biases in Online Product Reviews. MIS Quarterly, 2, 449-471. https://doi.org/10.25300/MISQ/2017/41.2.06

[6] Dellarocas, C., Zhang, X.M. and Awad, N.F. (2004) Exploring the Value of Online Product Reviews in Forecasting Sales: The Case of Motion Pictures. Journal of Interactive Marketing, 21, 23-45. https://doi.org/10.1002/dir.20087

[7] Duan, W., Gu, B. and Whinston, A.B. (2005) Do Online Reviews Matter?-An Empirical Investigation of Panel Data. Decision Support Systems, 45, 1007-1016. https://doi.org/10.1016/j.dss.2008.04.001

[8] Clemons, E., Gao, G. and Hitt, L. (2006) When Online Reviews Meet Hyper Differentiation: A Study of the Craft Beer Industry. Journal of Management Information Systems, 23, 149-171. https://doi.org/10.2753/MIS0742-1222230207

[9] Benlian, A., Titah, R. and Hess, T. (2012) Differential Effects of Provider Recommendations and Consumer Reviews in E-Commerce Transactions: An Experimental Study. Journal of Management Information Systems, 29, 237-272. https://doi.org/10.2753/MIS0742-1222290107

[10] Young Kwark, J.C. (2014) Online Product Reviews: Implications for Retailers and Competing Manufacturers. Information Systems Research, 19, 182-201.

[11] Ben Liu, Q.Q. and Karahanna, E. (2017) The Dark Side of Reviews: The Swaying Effects of Online Product Reviews on Attribute Preference Construction1. MIS Quarterly, 2, 427-448. https://doi.org/10.25300/MISQ/2017/41.2.05

[12] Yang, S. and Xu, C. (2013) The Impact Mechanism of the Usefulness of Online Product Reviews-Based on the Perspective of Virtual Community. Seeking, 3, 249-251.

[13] Lee, M. and Youn, S. (2015) Electronic Word of Mouth (eWOM): How eWOM Platforms Influence Consumer Product Judgment. International Journal of Advertising, 28, 473-499. https://doi.org/10.2501/S0265048709200709

[14] Zhou, S.S. (2016) Research on the Formation of Online Review Dynamics and Its Influence Mechanism. Zhejiang University, Hangzhou.

[15] Hong, H., Xu, D. and Wang, G.A. (2017) Understanding the Determinants of Online Review Helpfulness: A Meta-Analytic Investigation. Decision Support Systems, 102, 1-11. https://doi.org/10.1016/j.dss.2017.06.007

[16] Yin, G.A., Liu, W.W. and Zhu, S. (2012) What Makes a Helpful Online Review? The Perspective of Information Adoption and Social Network. Library and Information Service, 56, 140-147. 
[17] Zhang, Y.H. and Li, Z.W. (2016) Analysis of the Factors that Influence Online Reviews Helpfulness: Based on the Regulating Effect of Product Type. Management Reviews, 28, 123-132.

[18] Huang, Y., Li, C. and Wu, J. (2017) Online Customer Reviews and Consumer Evaluation: The Role of Review Font. Information \& Management, 55, 1-11.

[19] Yan, Q. and Mang, Y. (2013) Factors Affecting the Perceived Usefulness of Online Reviews-An Empirical Study Based on Online Film Reviews. Chinese Journal of Management Science, 21, 126-131.

[20] Song, T.T., Yi, C. and Huang, J. (2017) Whose Recommendations Do You Follow? An Investigation of Tie Strength, Shopping Stage, and Deal Scarcity. Information \& Management, 54, 1072-1083. https://doi.org/10.1016/j.im.2017.03.003

[21] Hernández-Ortega, B. (2018) Don’t Believe Strangers: Online Consumer Reviews and the Role of Social Psychological Distance. Information \& Management, 55, 31-50. https://doi.org/10.1016/j.im.2017.03.007 